\title{
Efficacy of Chewing Sticks Extract on the Agent of Dental Carries Isolates
}

\section{Adeoti OM ${ }^{1,3 *}$, Adedoja SA ${ }^{2}$, Adedokun EO ${ }^{2}$, Olaoye $\mathrm{OJ}^{2}$, Abiola $\mathrm{AO}^{2}$ and Okesipe FO ${ }^{1}$}

${ }^{1}$ Department of Science Laboratory Technology, Biology Unit, Nigeria

${ }^{2}$ Department of Food Science Technology, the Oke-Ogun Polytechnic, Saki, Oyo State, Nigeria

${ }^{3}$ Department of Pure and Applied Biology, Microbiology Unit, Ladoke Aknitola University of Technology, P.M.B 4000, Ogbomoso, Nigeria

${ }^{*}$ Corresponding author: Adeoti OM, Department of Science Laboratory Technology, Biology Unit, Microbiology, Nigeria, Tel: 08067285175; Email: txy23m@yahoo.com

Received date: Decemeber 13, 2019; Accepted date: February 20, 2020; Published date: February 27, 2020

Citation: Adeoti OM, Adedoja SA, Adedokun EO, Olaoye OJ, Abiola AO, et al. (2020) Efficacy of Chewing Sticks Extract on the Agent of Dental Carries Isolates. Arch Clin Microbiol Vol. 11 No. 1:101

\section{Abstract}

The preferred part or parts are cleaned with water to remove dirts then cut to a convenient length which varies from $15-30 \mathrm{~cm}$ long and tied into a bundle. The aim of this study was to determine the efficacy of chewing stick on the biological agents of dental carries isolates. Aqueous extracts of five different chewing stick Fagaraxanthoxyloides pako ata, Vernonia amygdalina pako ewuro, Anogeissus leiocarpa pako ayin, Azadirachta indica pako dogoyaro, Prosopis africana mesquite from different location-Sango, Gbawojo market in Saki Oyo State, were tested against isolated microorganisms from the plaque sample of five different individuals of dental carries without previous antibiotic history. The colonial, morphological microscopic and biochemical identification of the isolates were also performed. All the extracts from the selected chewing stick showed good antimicrobial activity against all the isolated microorganisms. It was observed that extract from Anogeissus leiocarpa at 500 $\mathrm{mg} / \mathrm{ml}$ showed a maximum zone of inhibition $(27 \mathrm{~mm})$ against Klebsiella while extract of $V$. amygdalina at 500 $\mathrm{mg} / \mathrm{ml}$ produced a maximum zone of inhibition of $(28$ $\mathrm{mm}$ ) against Streptococcus but extract of Fagaraxanth oxyloides exhibited a maximum zone of inhibition (27 $\mathrm{mm}$ ) against E. coli and extract of Azadirachta indica and Prosopis africana produced a maximum zone of inhibition of $(23 \mathrm{~mm}$ and $33 \mathrm{~mm})$ respectively at $500 \mathrm{mg} / \mathrm{ml}$. The present study confirmed the use of these Chewing stick in oral hygiene since their potential anti plaque effect is likely to complement the mechanical plaque removing property of chewing sticks. The results of the study possess inhibitory potentials against bacteria present in dental plaque mainly on aerobes. Chewing stick could be recommended in community for oral health program because they are readily available and cheaper.

Keywords: Chewing stick; Anti-plaque; Hygiene; Antibacterial; Dental

\section{Introduction}

In Nigeria, as in other developing countries, a very significant proportion of or facial disease (a condition characterized by persistent enlargement of the soft tissues of the mouth, lips and the areas around the mouth on the face) are due to microbial infection [1]. This being the case, there is widespread use of antibiotics in dental practice in these regions and this gives microorganism enhanced opportunities for the development of resistance to a broad spectrum of antibiotics.

Antibiotics are also widely used and misused in the management of other infections within the region [2]. The need to conserve antibiotics in order to prevent the selection of antibiotic resistant organisms has now been recognized and there is therefore the need to look for non-antibiotic substance with proven antimicrobial activity which can be used in the treatment of microbial infections, including those that are encountered in dental practice.

Chewing sticks are used widely in Africa and Asia as a means of maintaining oral hygiene [3]. They are made from the roots, twigs or stem of a plant. The preferred part or parts are cleaned with water to remove dirt, cut to a convenient length which varies from $15-30 \mathrm{~cm}$ long, and field into a bundle. The user holds one end directly in how mouth and chews it into a fibrous brush like fringe, which is used to scrub the surfaces of the teeth. A combination of vertical and horizontal strokes of the "brush" on tooth surfaces removes plaque. About five minute of complete devotion to this existence is deemed adequately to achieve good cleaning. Chewing sticks obtained from a variety of selected plants are used as a traditional method of mechanical oral hygiene by up to $80-90 \%$ of Nigerians. Almas, 2004 have demonstrated chewing sticks are at least as effective as tooth brushes, and their use has been encouraged by the WHO apart from their mechanical effects many of these chewing stick have been shown to have significant antimicrobial activity against a broad spectrum of microorganism. Therefore mechanical removal of plaque using chewing sticks in needed to inhibit the action of bacteria as well as chemically killing the bacteria and other pathogens responsible for dental carries. 
Different oral hygiene methods have been in practice to defeat widely common disease such as dental carries and oral infections. Various chemical and mechanical approaches are being used for maintaining good oral hygiene. Due to increasing awareness and expected evolving population, the use of safe, effective and economical products have expanded drastically and vary from country to country and from culture to culture $[3,4]$. Chewing sticks selected and prepared from the twigs, stem or roots from a variety of plant species have been practiced for thousands of years in Africa, Asia, the Middle East and the Americans [5]. School children in the mainly rural province of Matabeleland South in Zimbabwe were examined for dental caries and interviewed was also studies in 348 chiltrum from five school classes in Asella, Ethiopia [6]. Various clinical studies have shown that chewing sticks, which properly used, can be as efficient as tooth brushes in removing dental plaque due to the combined effect of mechanical cleaning and enhanced salivation [3]. Chewing sticks selected and prepared from the twigs, stem or roots from a variety of plant species have been practiced for thousands of years in Africa, Asia, the Middle East and the Americans [5]. School children in the mainly rural province of Matabele land South in Zimbabwe were examined for dental caries and interviewed was also studies in 348 chiltrum from five school classes in Asella, Ethiopia [6]. Various clinical studies have shown that chewing sticks, which properly used, can be as efficient as tooth brushes in removing dental plaque due to the combined effect of mechanical cleaning and enhanced salivation [6]. The use of chewing stick became very popular in the Muslim world including several African and Arab countries [4] presented study with an aim to evaluate the efficacy of extracts of some selected chewing sticks on the agent of dental carries isolates.

\section{Justification}

The oral hygiene of habitual chewing stick and toothbrush used in children in the age group of 10-13 years. They reported that though at baseline, chewing stick user exhibit statistically significant more plaque, but their gingival condition was comparable with toothbrush users. The chewing stick and the toothbrush users had reduced their plaque and gingival bleeding scores significantly to the same extent.

\section{Materials and Methods}

\section{Source of plant material}

The chewing stick selected was obtained from the root of Azadirachta india (Neem), Vernonia amygdalina (Bitter leaf), Fagara zanthoxyloides, Prosopis africana (mesquite) and Anogesissus leiocarpus. They were all collected from Saki in Oke-Ogun area (woody savanna vegetation) of Oyo State, Nigeria. The plant parts were authenticated by a Botanist at the Department of Biology. The chewing stick were washed under running tap water, to remove dirty, the sample were shaded dried for 7 days at room temperature to curb distortion in the composition of active principle in the chewing stick [7].

\section{Collection of plaque sample}

Dental plaque from five different individual were picked with swabbed three times with sterile cotton wool to remove debris and saliva (Table 1).

Table 1 Colonial and morphological characteristics of bacterial isolates.

\begin{tabular}{|l|l|l|l|l|}
\hline $\begin{array}{l}\text { Colonial } \\
\text { characteristics }\end{array}$ & Sample A & Sample B & Sample C & $\begin{array}{l}\text { Sample } \\
\text { D }\end{array}$ \\
\hline Colour & $\begin{array}{l}\text { Creamy } \\
\text { white }\end{array}$ & White & Yellow & Bulf \\
\hline Elevation & Raised & Flat & Raised & Raised \\
\hline Edge & Entire & Irregular & $\begin{array}{l}\text { Filamentou } \\
\mathrm{S}\end{array}$ & Distinct \\
\hline Shape & $\begin{array}{l}\text { Filamentou } \\
\mathrm{S}\end{array}$ & Punctiform & Circular & Irregular \\
\hline Optical Feature & Opaque & $\begin{array}{l}\text { Translucen } \\
\mathrm{t}\end{array}$ & $\begin{array}{l}\text { Transparen } \\
\mathrm{t}\end{array}$ & Dull \\
\hline
\end{tabular}

\section{Isolation of bacteria}

The test organism was isolated directly from an infected tooth, the tooth was then swabbed with sterile cotton wool swab and immediately streak on a sterile blood agar in duplicate, the plate will be incubated at 37 degree per Celsius for 24 hours. Characteristics colonies were picked from the plate and purified by repeated sub culturing. Pure colonies were streaked on nutrient agar plates were incubated at 37 degree per Celsius for 24 hours (Figure 1).

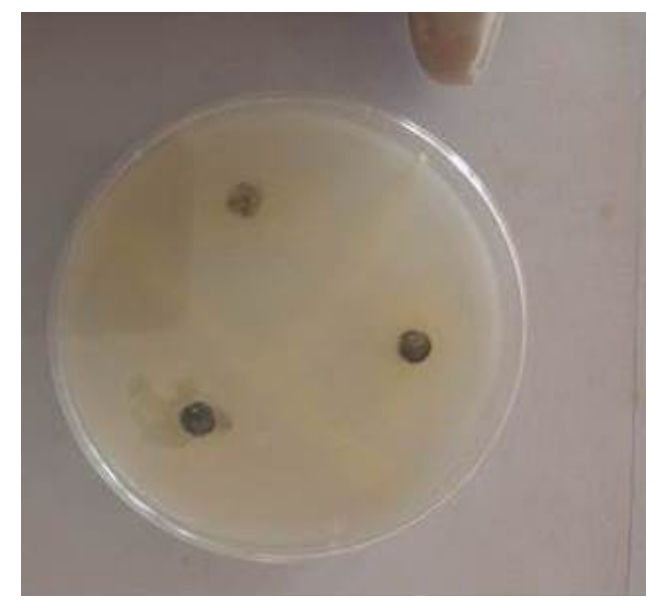

Figure 1 Zone of inhibition of Azadirachta indica against Staphylococcus aureus.

\section{Extraction Procedure of Chewing Stick}

The dried Samples were well pulverized into a fine powder with a mixer grinder. The powder was stored air tight aseptic container 28 degree per Celsius for subsequent use. 


\section{Procedure}

$5 \mathrm{~g}$ of Azadirachta indica (Neem), Vernonia amygdalina (bitter leaf), Faqgara zanthoxyloides, Prosopis africana (mesquite) and Anogeisus leiocarpus was poured into a bottle and filled with $100 \mathrm{ml}$ of sterile distilled water and left to soak for 7 days. The supernatants were filtered using Whatman NO. 1 filter paper, then label and stored. It was measured according to the manufacturer's prescription of 28 grams into100 $\mathrm{ml}$ of distilled water and was shaken vigorously after being covered and then sealed with cotton wool in an Aluminum foil. All this process was done in a well sterile environment which was being sprinkled and cleaned with ethanol and other dis-infecting agents (Table 2).

Table 2 Morphological characteristics.

\begin{tabular}{|l|l|l|l|l|}
\hline & Sample A & Sample B & Sample & Sample D \\
\hline $\begin{array}{l}\text { Gram } \\
\text { Staining }\end{array}$ & Positive & cocci (+ve) & Negative & Negative \\
\hline $\begin{array}{l}\text { Spore } \\
\text { staining }\end{array}$ & Positive & Positive & Negative & Positive \\
\hline
\end{tabular}

\section{Inoculation of agar}

After sterilization of the media, it was allowed to cool at 45 degree per Celsius then blood was added to form blood agar and shake together and the agar was poured in each petri dish and rock gently and allowed to solidify properly. Then a streak was performed in which the debris and saliva from the infected tooth was inoculated and incubated at $37^{\circ} \mathrm{C}$ overnight. The same principle was used to prepare other agar such as EMB, Mac Conkey, MRS and SSA according to the manufacturers' instructions.

\section{Sub-Culturing of microbial growth}

The prepared nutrient agar was poured into the petri dishes, it was allowed to solidify and inoculating loop used to pick each colony growth on the mix plates were isolated and subcultured by planting on a new set of sterile nutrient agar was by streaking for bacteria an $d$ inoculated appropriately to get the pure cultures of the isolates (Table 3 ).

Table 3 Gram staining properties of bacteria present in the tooth plaque.

\begin{tabular}{|l|l|l|}
\hline Name of bacteria & Gram Staining & Morphology \\
\hline Staphylococus aureus & Gram positive & Cocci in cluster \\
\hline Escherichia coli & Gram Negative & Rod Shape \\
\hline Bacillus subtilis & Gram Positive & Rod Shape \\
\hline Kleibsiella spp. & & \\
\hline
\end{tabular}

\section{Characteristic of bacteria isolates}

Pure bacterial isolates were sub-culture on the nutrient agar plates before characterization. The colonial characteristic of each colony were study with attention on shape, margin (edge of colony), elevation, color and optical features of the colony, surface tension, consistency. For the bacteria characteristics 18-24 hour old culture were used, the bacterial isolates were further subjected to staining techniques before microscopic examination. Biochemical test such as coagulase test and catalase were used to confirm the isolate (Figure 2).

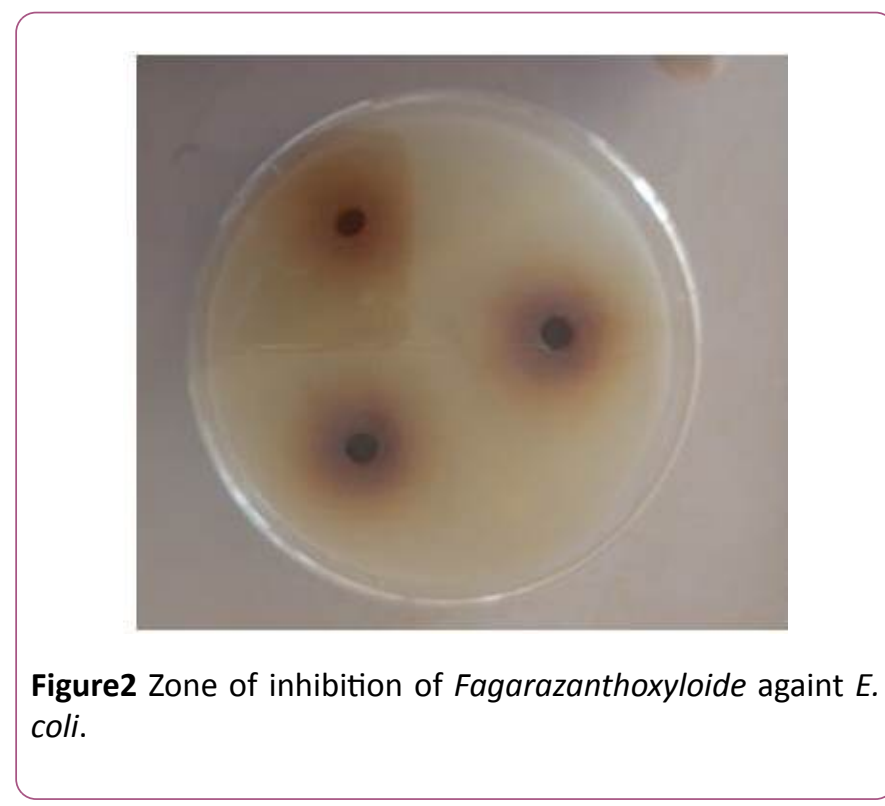

\section{Determination of Inhibitory Properties}

Ability of isolate to grow in extract: This was establishing if the different extracts had inhibitory properties. $0.25 \mathrm{~m}$ of the isolate obtained from a 24 hours broth culture was introduced into sterile test tubes containing $2.5 \mathrm{ml}$ undiluted extracts. The tubes were incubated at 37 degree Per Celsius for 24 hours. The broth cultures were sub cultured onto agar plates by the streaking method to observe for growth (Table 4).

Table 4 Degree of inhibition per the extract.

\begin{tabular}{|l|l|l|}
\hline & Cold water & Hot water \\
\hline F. xanthoxyloides (pako-ata) & +++ & +++ \\
\hline A. leiocarpus(pako-ayin) & + & + \\
\hline V. amygdalina (pako-ewuro) & ++ & ++ \\
\hline A. indica (pako-dogoyaro) & ++ & ++ \\
\hline P. africana (pako-ayin) & + & + \\
\hline
\end{tabular}

Bioassay: The test organism was sub cultured three times in fresh media to obtain a more vigorous population. $1 \mathrm{ml}$ of cultured was aseptically transferred into sterile petri dishes. 15 $\mathrm{ml}$ of molten nutrient agar was poured into the same plates. It was allowed to gel and dry. This was done in duplicates. A sterile corn borer of size $5 \mathrm{~mm}$ in diameter was pushed into the agar was pushed into the agar and agar plugs were removed creating a well/ditch. To each ditch was added chewing stick extracts from cold water while sterile distilled water were used as control. 
All plates were labeled and allowed 2 hour for proper diffusion of the extracts before incubation at 37 degree per Celsius for 24 hours. The mean zone of inhibition were measured and recorded to the nearest $\mathrm{mm}$ diameter. A mean inhibition zone greater than $2 \mathrm{~mm}$ was used as the minimum threshold [8].

\section{Results}

The activities of microbial oral flora in causing different types of oral infection most especially dental caries are frequently investigated [9]. It is well documented that the bacteria of the general Streptococcus, Lactobacillus, Corynebacterium and Staphylococcus are normal flora of the mouth and can as well cause dental caries [10].

Many of the observations made in this study are consistent with the existing reports. In the study of dental caries, the most prevalent organisms in this infection were Streptococcus mutans and Lactobacillus sp. Lactobacillus thrives in the acid environment created by S. mutans Caldwell and Leliner. The data presented in tables above confirmed the earlier reports $[8,11]$.

They found out that some African chewing sticks have been found to be effective against some Gram positive organisms. They also found out that most of the Nigerian chewing sticks were effective in preventing and curing many oral infections including dental caries.

\section{Discussion}

Generally $V$. amygdalina showed a minimal antibacterial activity from all the extracts used. A. Leiocarpus produced a relatively intense antibacterial activity against the lactobacillus $s p$. From all the extracts used while F. xanthoxyloides showed no inhibition or antibacterial effect on the test bacteria with the water extract. This result compliments earlier observation by Rotimi [12] who tested some Nigerian chewing stick extracts against Bacteroides, gingivaly and Bacterodes melaninogenicus. They reported no appreciable inhibition with F. Xanthoxyloides. The same result was also reported earlier [8], Zanthoxyleim giletti (which is generally the same as $F$. Xanthoxyloides Lowe Show no inhibition or antibiotic effect on Staphylococcus sp.

\section{Conclusion}

In all dental caries experiences, prevention is a worthy aim, which should be safely and effectively used for the attainment of improved dental health. Much research has been carried out regarding the cause, nature, treatment and prevention of dental caries but thus far, this great effort has not provided the means of eliminating the disease. Study has however provided some methods for the partial control and prevention of these dental diseases. To this end, the study has revealed that dental caries can be prevented by minimizing our sugar intake since the infection is caused by an organism which metabolizes sucrose into lactic acid. Due to the inhibitory activities of some chewing sticks most especially $A$. leiocarpus against a microorganism associate with dental caries.

\section{References}

1. Ndukwe KC, Okeke IN, Lamikanra A, Adesina SK, Aboderin O (2005) Antibacterial activity of aqueous extracts of selected chewing sticks. J Contemp Dent Pract 3: 086-094.

2. Okeke IN, Lamikanra A, Edelman R (2009) Socioeconomic and behavioral factors leading to acquired bacterial resistance to antibiotics in developing countries. Emerging Infect Dis 5: 18-27.

3. Darout IA, Christy AA, Skaug N, Egeberg PK (2000) Identification and quantification of some potentially antimicrobial anionic components in miswak extract. Indian J Pharmacol 32: 11-14.

4. Almas K, Al-Zeid Z (2004) The immediate antimicrobial effect of a toothbrush and miswak on cariogenic bacteria: a clinical study. J Contemp Dent Pract 15: 105-114.

5. Al-Otaibi M (2004) The miswak (chewing stick) and oral health. Studies on oral hygiene practices of urban Saudi Arabians. Swedish dental journal. Supplement 167: 2-75.

6. Olsson B (2008) Efficiency of traditional chewing sticks in oral hygiene programs among Ethiopian school children. Community dentistry and oral epidemiology 6: 105-109.

7. Eloff JN (2008) which extractant should be used for the screening and isolation of antimicrobial toothbrush as an oral hygiene aid. Clinical Prevention Dentistry. 12: 19-23.

8. Akande JA, Hayashi Y (2008) Potency of extract contents from selected tropical chewing sticks against Staphylococcus aureus and Staphylococcus auricularis. World J Microbiol and Biotechnol 14: 235-238.

9. Pinheiro ET, Gomes FA, Ferra CCR, Teixeira FB, Souza AA, et al. (2003) Evaluation of root canal microorganisms Isolated from teeth with endodontics failure and their antimicrobial susceptibility. Oral Microbiology and Immunology 18: 100-103.

10. Slots J (2007) The predominant cultivable microflora of advanced periodontitis. Scandinavian J Dental Caries Res 85: 114-121.

11. Fadulu SO (2005) The Antibacterial Properties of the buffered extract of chewing stick $s$ used in Nigeria. Plant Med 27: 122-126.

12. Rotimi VO, Laughon BE, Bartlett JG, Mosadomi HA (2008) Activities of Nigerian chewing stick extracts against Bacteroides gingivalis and Bacteroides melaninogenicus. Antimicrobial agents and Chemotherapy 32: 598-600. 